Rowan University

Rowan Digital Works

9-9-2019

\title{
Are Humans Natural? Part 2: Exploring Human-Nature Relational Values and the Balance of Nature
}

Nathan Ruhl

Rowan University

Follow this and additional works at: https://rdw.rowan.edu/oer

Part of the Biology Commons, and the Philosophy Commons

DOI: 10.31986/issn.2689-0690_rdw.oer.1014

Let us know how access to this document benefits you - share your thoughts on our feedback form.

\section{Recommended Citation}

Ruhl, Nathan, "Are Humans Natural? Part 2: Exploring Human-Nature Relational Values and the Balance of Nature" (2019). Open Educational Resources. 16.

https://rdw.rowan.edu/oer/16

This Curricular Materials is brought to you for free and open access by the University Libraries at Rowan Digital Works. It has been accepted for inclusion in Open Educational Resources by an authorized administrator of Rowan Digital Works. 
Title:

Are Humans Natural? Exploring human-nature relational values and the balance of nature

\section{Overview:}

This learning module is part of a series of modules that seeks to help students develop human-nature relational values. Relational values are more readily developed when the methods employed reference species/environments/landscapes/situations that students are familiar with already and may encounter during their everyday lives. In this activity students are asked to consider whether nature is in balance. The idea that nature is in balance extends deep into human history, but modern scientific evidence clearly demonstrates that nature is not in balance. Despite scientific evidence, the perception that nature is stable or in balance persists in human culture. This activity challenges misconceptions about how nature changes over time, demonstrates that this fallacy extends far back into human history, and explores our current scientific understanding.

\section{Goals:}

Relational values are promoted when students:

- Reflect on their individual relationship with nature

- Recognize humans are a connected component of nature subject to temporal change in the same way other species are

Learning goals in the biological sciences are reinforced when students:

- Make connections between the subject matter and their lives

- Know that science can be subjective and is not value-free

- Critically evaluate subjectivity to form an opinion about the validity of the conclusions of others.

- Draw upon previously learned material to understand novel concepts

- Better understand ecological and evolutionary processes

- Recognize links between biology and other academic disciplines

\section{User Guide:}

The worksheet below is intended to prompt classroom discussion and could be implemented as either homework or an in-class assignment. The instructor should leverage the worksheet to lead discussion during a class meeting. It is recommended 
that the instructor read the discussion points for instructors prior to the discussion. Parts of this assignment, and quotes used in the assignment, are based on Egerton, 1973.

Egerton FN. 1973. Concepts of the balance of nature. The quarterly review of biology, 48:2, 322-350.

\author{
Materials: \\ - Worksheet for students (last page below) \\ - Helpful hints for instructors (immediately below)
}

\title{
Part I:
}

This section introduces students to both the balance of nature theme and asks study to consider whether humans are natural. As a Quaker, Hicks did not believe that violence was the solution to problems and instead sought peaceful resolution and compromise. Hicks series of paintings, "Peaceable Kingdom", uses several recurrent themes emphasizing harmony/peace. William Penn is often depicted meeting with Native American ("Indian") leaders to form a treaty and large predators are depicted next to comparatively defenseless primary consumers.

Q1 and Q2: Students will pick up on the themes above without too much difficulty, but do not readily use the appropriate ecology terms. Encourage the students to frame the harmonious depiction against concepts/terms such as consumer-resource interactions, producers/consumers, trophic cascades, and ecological efficiency or energy assimilation.

Q3: Students will often claim that the humans ARE out of place and are NOT natural. Students usually point to the young human near the predator to support this argument. Steer the discussion toward the group of humans talking to each other. Are they natural? Native Americans are usually considered to have a much tighter/holistic/enlightened relationship with nature than European settlers or modern humans; are they natural? Hicks often depicts a large ship, made of naturally occurring materials; is the ship natural? What makes something natural vs. artificial?

\section{Part II:}

This section introduces students to the role of God(s) in keeping nature in balance, how humans perceive the world, and the scale at which human perception occurs.

Q4: According to the mythological outline (which has been simplified from the original for ease of use in this activity), the "natural" state is for nature to NOT be in balance and it is only through the action of a God that balance is achieved. With that in mind, is nature in balance? Is the relationship between the Gods in the myth equal/balanced? These are loaded questions and the discussion can easily devolve along theological and feminist lines of discussion. Consider allowing the students to explore these ideas within the time constraints of your course and take 
advantage of opportunities to bring the conversation back to the theme of balance/stability/equality over time.

Q5: This question is intended to redirect the discussion from Q4 to the scientific method. Students will usually focus on extreme events like volcanic eruptions and droughts when answering this question. Remind students that scale is important. Examples include scaling intensity (extreme vs. mild weather), time (climatic change vs. weather) and space (continental vs. local). Encourage discussion about human scales of perception. How do humans find truth and meaning? How do we explain the unexplained? Historical manifestations of science were reductionist, rooted in loosely controlled observation, very applied (e.g. when crops should be planted), and science/technology were synonymous. Modern science is not the same as technology and uses formalized deductive methods (hypothesis testing) with very carefully defined/controlled observations to answer both fundamental and applied questions. Science is a way of knowing. Society at large "knows" through inductive methods/observations at human scales of perception whereas scientists "know" through carefully defined observations that extend beyond human scales of perception.

\section{Part III}

This section challenges students to interpret a complex/challenging paragraph and contextualize its ecological meaning. This section also demonstrates that people have been making observations about the natural world for a long time, but that perceptions about how biological processes occur may be erroneous. This section continues the theme about how humans perceive the world, the role of God(s) in governing over the natural world, and the differing approaches to observation taken by modern scientists and society at large from Part II.

Q6: Consumer-resource interactions, life history traits, survivorship curves, K-selection, semelparity/iteroparity and more. Ask students to explain each of these phenomena.

Q7: The world is organized, stable, in balance, meant to be, predetermined, etc. by God. Contrast this statement with the rest of the paragraph, where the author demonstrates a basic misunderstanding of how reproduction occurs in lions. Can humans perceive "Gods plans"? Is nature in balance? Can it be known whether nature is in balance? Does the existence (or not) of a God(s) dictate whether nature is in balance?

\section{Part IV}

This section is intended to prompt a discussion of the importance of evolution to understanding how organisms/nature changes over time. Whether or not nature is in "balance" depends on definition of balance and the scale at which observations are made. Balance definitions range from "to remain steady", to "self-stabilizing", symmetrical or equal. What appears balanced at the human scale of temporal perception may not be balanced in geological time. The same is true of variation in space.

Q8: Predator-prey cycles, carrying capacity. 
Q9: Elton espouses the modern understanding of how populations and communities change over time. Populations, communities, ecosystems, and the planet are not in balance or stable over time; they are all constantly changing. Observational techniques that were not available in Elton's time would likely reinforce his view. If nature is not in balance, why are there ecological concepts that seem to suggest otherwise (see Q6, Q8)? Nothing in biology makes sense except in the light of evolution. Discuss unifying and balancing power of selection for ecological/functional traits. For example: The interplay of ecological concepts (e.g. population size) with evolution (change in allele frequency) during predator-prey cycles.

\section{Sample Implementation:}

This activity was originally developed for a 300-level Environmental Science course populated by third- and fourth-year biology majors and used as part of a hybrid lecture-lab activity. The discussion described in this module formed the lab portion of the exercise. This activity draws from many social and humanities sub-disciplines in addition to biology and may therefore have some utility across a wide range of courses, though the discussion would likely have to be adapted to the specific course goals. As it is presented here, the activity would be appropriate for any upper-level ecology course. 
Names:

\section{Part I:}

Edward Hicks was a Quaker and self-taught artist. His paintings and his worldview were informed by the bible, specifically Isaiah 11:6, which he modified to fit his time and place.

Paintings: https://en.wikipedia.org/wiki/Edward Hicks

1) Study Hicks' "Peaceable Kingdom" paintings at the link above. What are some words you would use to describe the paintings?

2) What do you think Edward Hicks is trying to convey with his art? Would he use the same words that you used in \#1?

3) Are humans a natural component of the depicted scenes? Hint: think about the passage above. 


\section{Part II}

Persephone was the Greek goddess of the spring. Hades, king of the underworld took a liking to Persephone (Daughter of Demeter, the Greek Goddess of the Harvest) and kidnapped her to the underworld to be married. This plunged the world into perpetual winter. Mortal men begged Zeus to intervene, and a deal was struck whereby Persephone would be allowed to return to Earth for half of the year, and must return to the underworld for the other half of the year.

4) How does this story relate to the "balance of nature" theme (Part 1)

5) What are some features of the natural world that the ancient Greeks might have observed and attributed to this story and the relationships between the gods? 


\section{Part III:}

Herodotus is the father of modern history. We refer to him as such because he retold historical events in a systematic, logical, and organized fashion. This approach is in some ways similar to the approach modern science takes to knowledge, but Herodotus did not check his sources and much of his retelling of history is therefore altered by incorrect information. Nevertheless, we find in his writings the underpinnings of Ecology:

"Of a truth Divine Providence does appear to be, as indeed one might expect beforehand, a wise contriver. For timid animals which are a prey to other are all made to produce young abundantly, that so the species may not be entirely eaten up and lost; while savage and noxious creatures are made very unfruitful. The hare, for instance, which is hunted alike by beast, birds, and men, breeds so abundantly as even to superfetate, a thing which is true of no other animal. You find in a hare's belly, at one and the same time, some of the young all covered with fur, others quite naked, others again just fully formed in the womb, while the hare perhaps has lately conceived afresh. The lioness, on the other hand, which is one of the strongest and boldest of brutes, bring forth young but once in her lifetime, and then a single cub; she cannot possibly conceive again, since she loses her womb at the same time that she drops her young. The reason of this is that as soon as the cub begins to stir inside the dam, his claws, which are sharper than those of any other animal, scratch the womb..."

6) What modern ecological relationships has Herodotus identified?

7) What does the first sentence of the quote above mean? 


\section{Part IV:}

Writing in 1714, William Derham first expressly articulated the balance of nature concept:

"The balance of the animal world is, throughout all ages, kept even, and by a curious harmony and just proportion between the increase of all animals, and the length of their lives, the world is through all ages well, but not over-stored"

8) What modern ecological paradigms has Derham identified?

200 years later (in the 1930's), famed zoologist Charles Elton-- wrote:

"The balance of nature does not exist, and perhaps never existed. The numbers of wild animals are constantly varying to a greater or less extent, and the variations are usually irregular in period and always irregular in amplitude. Each variation in the numbers of one species causes direct and indirect repercussions on the numbers of the others, and since many of the latter are themselves independently varying in numbers, the resultant confusion is remarkable"

9) Is Elton correct? How might modern scientific equipment (GPS collars, radio telemetry, computers, complex statistics and mathematical models, etc.) influence Elton's worldview? 